\title{
GilR, an Unusual Lactone-Forming Enzyme Involved in Gilvocarcin Biosynthesis
}

\author{
Madan Kumar Kharel, Pallab Pahari, Hui Lian, and Jürgen Rohr \\ University of Kentucky, Department of Pharmaceutical Sciences College of Pharmacy, 725 Rose \\ Street, Lexington, KY 40536-082 (USA)
}

\section{Keywords}

biosynthesis; $C$-glycosides; dehydrogenases; gilvocarcins; lactones

\begin{abstract}
Lactones are common structural moieties found in various important secondary metabolite natural products from microorganisms, fungi, or plants. These include gilvocarcin $\mathrm{V}(\mathrm{GV}, \mathbf{1})$, lovastatin (2), artemisinin (3), pentalenolactone (4), erythromycin A (5), novobiocin (6), camptothecin (7), and mycolactone A (8; Figure 1$)$. In many cases lactones modulate the biological activity of molecules directly by interacting with target sites (as in camptothecin) $[1,2]$ or indirectly by providing structural rigidity to the molecule (as in erythromycin). Lactones have also been found or proposed as intermediates of biosynthetic pathways, for example, in jadomycin, gilvocarcin, mithramycin, and urdamycin biosynthesis, in which interim lactone formation is crucial for the installation of polar residues of the final structures. [3-5] Interestingly, the ways through which nature installs lactones in such secondary metabolites are found to be limited to two general routes, namely: 1) through the intramolecular condensation between a hydroxyl group and a carboxylic acid or an ester (Scheme 1, route A), and 2) through Baeyer-Villiger oxidation of a cyclic ketone (Scheme 1, route B). The vast majority of the macrolide lactones are generated through thioesterase (TE) domain mediated intramolecular condensation of thioester and alcohol,[6-8] whereas lovastatin lactone formation is truly $\mathrm{pH}$ dependent.[9] Literature on Baeyer-Villiger monooxygenases (BVMO)catalyzed lactone formation in natural products is rapidly emerging. $[4,10]$ In contrast, lactone generation through the oxidation of a hemiacetal moiety (Scheme 1, route C) was only found in primary metabolism, particularly the pentose phosphate pathway. We report here this rare lactone formation for the first time as a step in the biosynthetic pathway of a secondary metabolite, gilvocarcin V (GV).
\end{abstract}

GV, a potent antitumor drug is the principal product of Streptomyces griseoflavus Gö3592. It exhibits high potency against various tumor cell lines at a low concentration with low in vivo cytotoxicity.[11,12] Gilvocarcin has an UV-fluorescent coumarin-based benzo[d]naptho-[1, $2 b$ ]pyran-6-one backbone that is linked through a C-glycosidic bond to the rare sugar $\mathrm{D}$ fucofuranose.[13] The antitumor activity of GV is achieved through a light-mediated [2+2]cycloadduct formation of its vinyl side chain with thymidine residues of the DNA.[14-16] An additional unique component of GV's antitumor mechanism-of-action is the selective GVmediated cross-linking of histone H3 and DNA.[17] The formation of the lactone moiety of $\mathrm{GV}$ is particularly important because it establishes the third ring, thereby fixing the aromatic

(C) 2009 Wiley-VCH Verlag GmbH \& Co. KGaA, Weinheim

Fax: (+ 1) 859-257-7564 jrohr2@email.uky.edu.

Supporting information for this article is available on the WWW under http://dx.doi.org/10.1002/cbic.200900130. 
naphthol moiety and the styrene moiety of the molecule in the same plane and locking up their free rotation. In-depth understanding of the mechanism of lactone formation and its occurrence in the sequence of events of GV biosynthesis is crucial for the generation of GV analogues through combinatorial biosynthesis.

Recently, the GV gene cluster has been isolated, and the roles of various gene products in GV biosynthesis have been determined through heterologous expression, gene inactivation, gene complementation, and feeding of pathway intermediates.[3,13,18-20] Sequence analysis revealed four candidate oxygenases (GilOI, GilOII, GilOIII, GilOIV) that could potentially be involved in the lactone formation.[13] The individual gene deletion results showed that GilOIII is responsible for the formation of the vinyl side chain, and the remaining three oxygenases partake in a post-polyketide synthase (post-PKS) oxidative cascade prior to lactone formation, which includes the 5,6-bond cleavage of an angucyclinone intermediate (Scheme 3).[18-20] Previous hypotheses proposed that the oxidative cleavage product was a di-acid, like 19 (Scheme 3), which then undergoes $\mathrm{C}-\mathrm{C}$ bond rotation and eventually establishes $\mathrm{GV}$ lactone by following route A of Scheme 1.[18,21-23] Surprisingly, the inactivation of one of the putative oxidoreductase genes, gilR, led to the accumulation of pregilvocarcin V (PreGV, 11; Scheme 2), the hemiacetal stereocenter of which was found in an $R, S$-mixture; this reflects an equilibrium between the hemiacetal and aldehyde/alcohol forms and suggests a direct role for GilR in GV lactone formation, but it remains unclear when exactly the GilR reaction occurs during GV biosynthesis.[3] We herein describe a detailed biochemical characterization of oxidoreductase GilR, and demonstrate that the purified protein catalyzes the dehydrogenation of $\mathbf{1 1}$ as the final step of the GV pathway. We also explored the substrate specificity of GilR for its potential application in combinatorial biosynthesis.

GilR (498 aa) belongs to an oxidoreductase family enzyme, whose amino acid sequence displays identity/similarity to putative dehydrogenases from various species: $43 / 57 \%$ to StfE (CAJ42334) from Streptomyces steffisburgensis, 41/55\% to a dehydrogenase (ZP 00377889) from Brevibacterium linens BL2, an FAD-binding protein (CAC22143) from Streptomyces coelicolor, and $41 / 58 \%$ to BusJ and SpnJ from butenyl spinosyn and spinosyn producer Saccharopolyspora pogona and Saccharopolyspora spinosa, respectively. Through an in vitro enzyme assay, SpnJ has been shown to be an oxidase that requires FAD to convert a secondary alcohol into a ketone in spinosyn biosynthesis.[24] Similarly, StfE has been proposed to serve as a dehydrogenase to generate a ketone from a secondary alcohol during the biosynthesis of steffimycin.[25] Other homologues of GilR were reported from the genome sequencing project, and have not been characterized yet. The conserved domain analysis revealed two hits: the Nterminal FAD-binding domain (pfam01565) and the C-terminal berberine-like domain (pfam08031). Pfam01565 family proteins belong to plant enzymes that utilize FAD as a cofactor and catalyze oxidation reactions, whereas pfam08031 family enzymes oxidize the Nmethyl group of (S)-reticuline into the C8 methylene bridge carbon of $(S)$-scoulerine in presence of FAD. To deduce the exact function of gilR, the gene was cloned into the pET28a vector, expressed in $E$. coli, and the generated N-terminal His-tagged protein was purified by using IMAC. The intense yellow color of the purified enzyme along with its typical FAD-like UV spectrum were a clear indication of bound FAD. Further analysis indicated that GilR exists in a monomeric form and FAD in fact is covalently bound to the enzyme (see the Supporting Information).

To test the activity of GilR, the enzyme was incubated with $\mathbf{1 1}$ in presence or absence of FAD. The HPLC-MS analysis of the assay mixture revealed the dramatic decrease of substrate $\mathbf{1 1}$ and the concomitant formation of $\mathbf{1}$ (see the Supporting Information). The addition of FAD did not alter the GilR catalysis; this confirms the saturation of GilR with covalently bound FAD. The results proved that GilR catalyzes the oxidation of the hemiacetal moiety of $\mathbf{1 1}$ to the lactone that is found in $\mathbf{1}$. The accumulation of significant amount of defuco-GV $\mathbf{9}$ by both the 
GilGT ( $C$-glycosyltransferase)- and GilU (deoxysugar 4-ketoreductase)-deletion mutants clearly indicated that GilR can also oxidize defuco-preGV 12 to shunt product $\mathbf{9}$, and the tethered defucofuranose residue is not necessarily required for the substrate binding.[19,26] Whereas the accumulation of $\mathbf{1 1}$ by the GilR-deletion mutant suggested that the Cglycosylation step occurs prior to the lactone formation, the possibility that the GilR reaction precedes the GilGT reaction could not be excluded, because GilGT might be flexible enough to glycosylate either $\mathbf{9}$ or $\mathbf{1 2}$. To address this ambiguity over the true substrate of GilR and the biosynthetic sequence, $\mathbf{1 2}$ was prepared semi-synthetically through a one-step diisobutyl aluminium hydride (DIBALH) mediated reduction of $\mathbf{9}$, and the kinetics of GilR catalysis were compared for both substrates. The $K_{\mathrm{m}}$ values of GilR were determined to be 117.0 and 93.4 $\mu_{\mathrm{M}}$ for $\mathbf{1 1}$ and 12, respectively (Table 1). However, the $k_{\mathrm{cat}}$ for $\mathbf{1 1}$ was found to be more than fourfold higher than for 12, and the ratio of $k_{\mathrm{cat}}$ and $K_{\mathrm{m}}$ for $\mathbf{1 1}$ appeared to be 3.5-fold higher than for 12; this clarified the former compound to be the true substrate of GilR. The kinetic data reveal that both the sugar-free substrate $\mathbf{1 2}$ and the sugar-containing substrate $\mathbf{1 1}$ bind equally well to the active site, but the sugar-containing product $\mathbf{1}$ can more easily leave the enzyme, possibly due to repulsion of active-site residues with sugar moiety O-atoms.

One of the major objectives of biosynthetic pathway studies is to generate natural product analogues through the exploitation of the substrate flexibility of pathway enzymes. Given the potential importance of the sugar moiety for the biological activity of the gilvocarcin-type drugs, alteration of the deoxy-sugar moiety of GV is a major emphasis to generate GV analogues by combinatorial biosynthesis. This requires relaxed substrate specificity of both GilGT and GilR. To test the flexibility of GilR regarding the $C$-glycosidically linked deoxysugar moiety, prechrysomycin A (13) was prepared through chemical reduction of chrysomycin A (10). The incubation of $\mathbf{1 3}$ with GilR under identical assay conditions barely generated 10, and this limited the complete kinetic study of the reaction. However, the specific activity of the enzyme for $\mathbf{1 3}$ was determined to be 2500 and 600-fold lower than for $\mathbf{1 1}$ and 12, respectively, thus indicating its poor specificity for a substrate analogue with a branched pyranose sugar moiety. However, we were previously able to generate a GV analogue with an extra hydroxyl group at the 4' position of the ${ }_{\mathrm{D}}$-fucofuranose through targeted inactivation of ketoreductase gene gilU. This analogue, however, maintained a five-membered sugar residue. [26] The poor conversion of $\mathbf{1 3}$ is caused by the branched pyranose, which likely imposes some steric hindrance in the binding pocket of GilR, which appears to be optimal for substrates with a 5-membered sugar residue.

In summary, the above results have clearly established that GilR, which is an FAD-dependent oxidoreductase, is responsible for oxidizing hemiacetal 11 to lactone $\mathbf{1}$. Because preGV exists as an equilibrium mixture of two diastereomers ( $R$ and $S$ configuration at the hemiacetal carbon), one could argue that through ring opening/closing GilR oxidizes the aldehyde to an acid, and the lactone forms spontaneously (via route A). However, this would require a more complex reaction, namely addition of water followed by dehydrogenation. The sequence of the gilR gene shows no hint for such a dual activity of its product, and an opened lactone form of GV has never been detected, not even in traces. Thus, the above-discussed direct dehydrogenation of the hemiacetal to the lactone is far more likely. In the primary metabolic pentose phosphate pathway, glucose-6-phoshate (G6P) dehydrogenase catalyzes a similar reaction by converting G6P to 6-phospho-d-gluconolactone. However, unlike GilR, this enzyme utilizes free $\mathrm{NADP}^{+}$.[27] Thus, GilR represents a new class of oxidoreductase in that it uses covalently bound FAD. Interestingly, no other cofactor was needed for the in vitro assay, and we assume that $\mathrm{FADH}_{2}$ reacts with dissolved oxygen to regenerate FAD. The results also clarify that lactone generation is the last step in GV (1) biosynthesis, and the enzyme is flexible enough to handle both sugar-tethered and sugar-free substrates, but its flexibility is limited by the nature of the linked deoxysugar. The unusual oxidative lactone generation found for the $\mathrm{GV}$ pathway might also play a role in the biosyntheses of other naturally occurring lactones, 
the pathways for which are yet to be elucidated. Intriguingly, the sequence of events for GV biosynthesis also requires another (intermediate) lactone $\mathbf{1 6}$ formation, here suggested to be a result of a Baeyer-Villiger oxidation, en route to $\mathbf{1 1}$ and $\mathbf{1}$, when the polyketide synthase product undergoes a series of dehydrations and oxidations, a decarboxylation and $O$ methylations (Scheme 3). GilGT-mediated glycosylation (12 to 11) followed by the GilRcatalyzed dehydrogenation finish the biosynthesis of $\mathbf{1}$. In the absence of GilGT, GilR catalyzes dehydrogenation of $\mathbf{1 2}$ to yield shunt product $\mathbf{9}$. Understanding the substrate-binding mode of GilR and widening its substrate specificity through site-directed mutagenesis might be necessary to generate further GV analogues by combinatorial biosynthesis.

\section{Supplementary Material}

Refer to Web version on PubMed Central for supplementary material.

\section{Acknowledgments}

The US National Institute of Health (grantCA 102102) is acknowledged for financial support of this work.

\section{References}

1. Hertzberg RP, Caranfa MJ, Hecht SM. Biochemistry 1989;28:4629. [PubMed: 2548584]

2. Jaxel C, Kohn KW, Wani MC, Wall ME, Pommier Y. Cancer Res 1989;49:1465. [PubMed: 2538227]

3. Kharel MK, Zhu L, Liu T, Rohr J. J. Am. Chem. Soc 2007;129:3780. [PubMed: 17346045]

4. Gibson M, Nur-e-Alam M, Lipata F, Oliveira MA, Rohr J. J. Am. Chem. Soc 2005;127:17594. [PubMed: 16351075]

5. Rix U, Remsing LL, Hoffmeister D, Bechthold A, Rohr J. ChemBioChem 2003;4:109. [PubMed: 12512084]

6. Ogasawara Y, Katayama K, Minami A, Otsuka M, Eguchi T, Kakinuma K. Chem. Biol 2004;11:79. [PubMed: 15112997]

7. Xue YQ, Wilson D, Sherman DH. Gene 2000;245:203. [PubMed: 10713461]

8. Tsai SC, Miercke LJW, Krucinski J, Gokhale R, Chen JCH, Foster PG, Cane DE, Khosla C, Stroud RM. Proc. Natl. Acad. Sci. USA 2001;98:14808. [PubMed: 11752428]

9. Kearney AS, Crawford LF, Mehta SC, Radebaugh GW. Pharm. Res 1993;10:1461. [PubMed: 8272408]

10. You Z, Omura S, Ikeda H, Cane DE. J. Am. Chem. Soc 2006;128:6566. [PubMed: 16704250]

11. Fischer C, Lipata F, Rohr J. J. Am. Chem. Soc 2003;125:7818. [PubMed: 12822997]

12. Krohn K, Rohr J. Bioorg. Chem. Deoxysugars, Polyketides Relat Classes: Synth. Biosynth. Enzym 1997;188:127.

13. Fischer C, Lipata F, Rohr J. J. Am. Chem. Soc 2003;125:7818. [PubMed: 12822997]

14. Knobler RM, Radlwimmer FB, Lane MJ. Nucleic Acids Res 1993;21:3920.

15. Knobler RM, Radlwimmer FB, Lane MJ. Nucleic Acid Res 1992;20:4553. [PubMed: 1408756]

16. Oyola R, Arce R, Alegria AE, Garcia C. Photochem. Photobiol 1997;65:802. [PubMed: 9155255]

17. Matsumoto A, Hanawalt PC. Cancer Res 2000;60:3921. [PubMed: 10919670]

18. Liu T, Fischer C, Beninga C, Rohr J. J. Am. Chem. Soc 2004;126:12262. [PubMed: 15453748]

19. Liu T, Kharel MK, Fischer C, McCormick A, Rohr J. ChemBioChem 2006;7:1070. [PubMed: 16795121]

20. Liu T, Kharel MK, Zhu L, Bright S, Rohr J. ChemBioChem 2009;10:278. [PubMed: 19067453]

21. Takahashi K, Tomita F. J. Antibiot 1983;36:1531. [PubMed: 6418705]

22. Carter GT, Fantini AA, James JC, Borders DB, White RJ. J. Antibiot 1985;38:242. [PubMed: 3997669]

23. Carter GT, Fantini AA, James JC, Borders DB, White RJ. Tetrahedron Lett 1984;25:255.

24. Kim HJ, Pongdee R, Wu QQ, Hong L, Liu HW. J. Am. Chem. Soc 2007;129:14582. [PubMed: 17985910] 
25. Gullon S, Olano C, Abdelfattah MS, Brana AF, Rohr J, Mendez C, Salas JA. Appl. Environ. Microbiol 2006;72:4172. [PubMed: 16751529]

26. Liu T, Kharel MK, Zhu L, Bright SA, Mattingly C, Adams VR, Rohr J. ChemBioChem 2009;10:278. [PubMed: 19067453]

27. Voet, D.; Voet, JG.; Pratt, CW. Fundamentals of Biochemistry: Life at the Molecular Level. 2nd ed.. Wiley; New York: 2006. p. 520 
<smiles>C=Cc1cc(OC)c2c(c1)-c(=O)-o-c1c3c-2c1-c(C1OC2C(O)[C@](C)(O)C(O1)[C@H]2O)=c-c=c-3O</smiles>

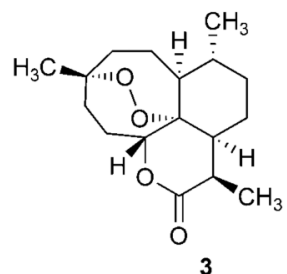<smiles>CC1=CC23C(C=C(C(=O)O)[C@H]2COC(=O)[C@]32CO2)C1C</smiles>

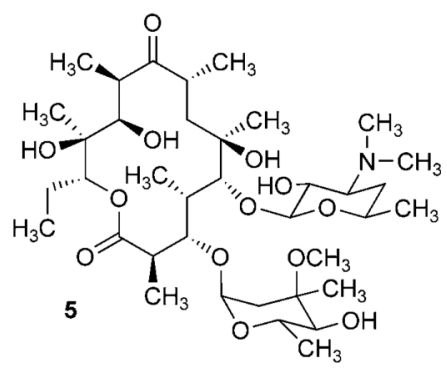<smiles>COC1C(Oc2ccc3c(O)c(NC(=O)c4ccc(O)c(CC=C(C)C)c4)c(=O)oc3c2C)OC(O)C(OC(N)=O)C1(C)C</smiles><smiles>CC[C@@]1(O)C(=O)OCc2c1cc1n(c2=O)Cc2cc3ccccc3nc2-1</smiles>

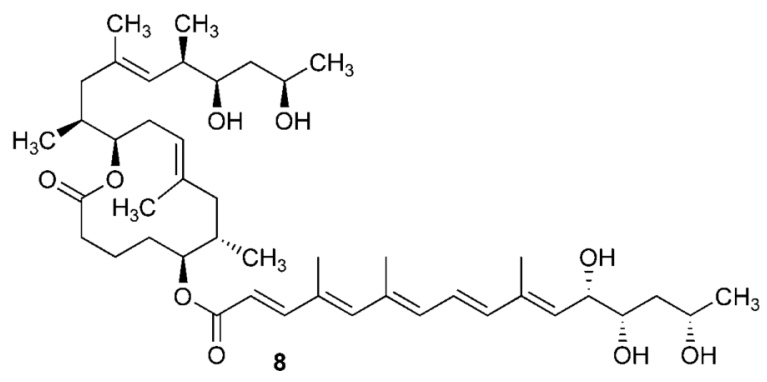

Figure 1.

Representative natural products with a lactone moiety. 


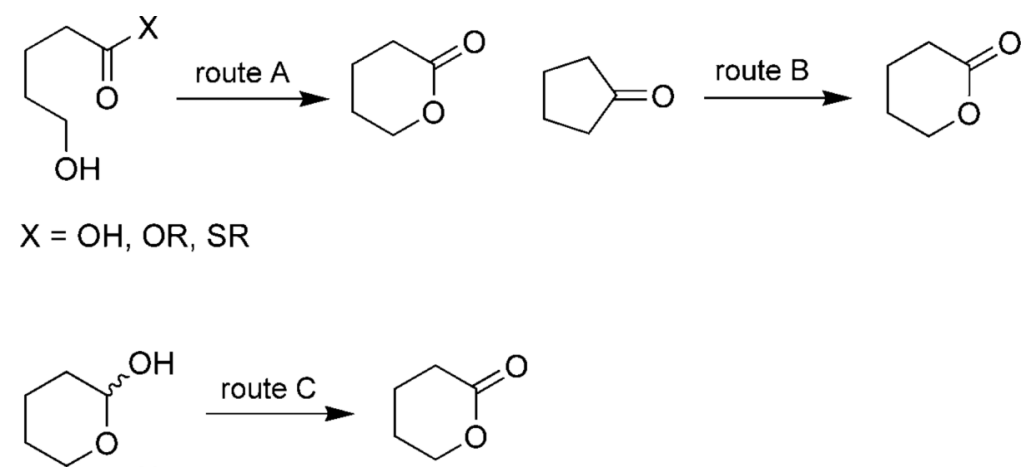

Scheme 1.

General routes for lactone formation in a variety of secondary metabolite natural products. 
<smiles>[R]c1ccc(O)c2c(OC)cc3c(oc(=O)c4cc(C=C)cc(OC)c43)c12</smiles>

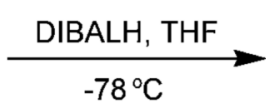<smiles>[R]c1ccc(O)c2c(OC)cc3c(c12)O[C@H](O)c1cc(C=C)cc(OC)c1-3</smiles>

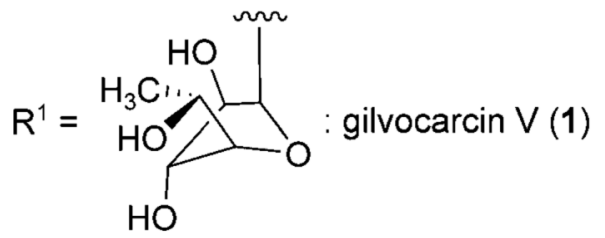

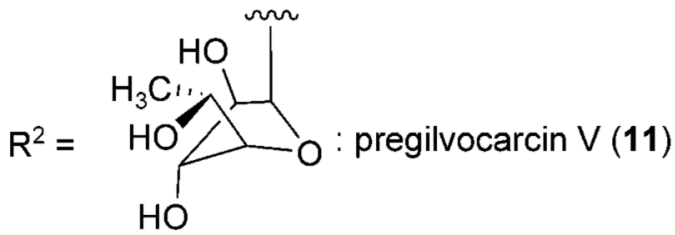

$\mathrm{R}^{1}=\mathrm{H}$ : defuco-gilvocarcin $\mathrm{V}(\mathbf{9})$

$\mathrm{R}^{2}=\mathrm{H}:$ defuco-pregilvocarcin $\mathrm{V}(\mathbf{1 2})$

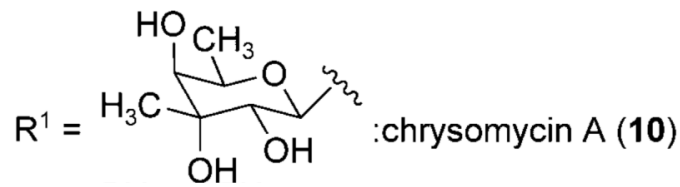

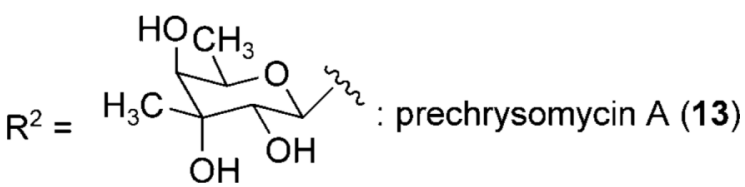

Scheme 2.

Generation of PreGV and analogues through chemical reduction of the respective lactone compounds. 


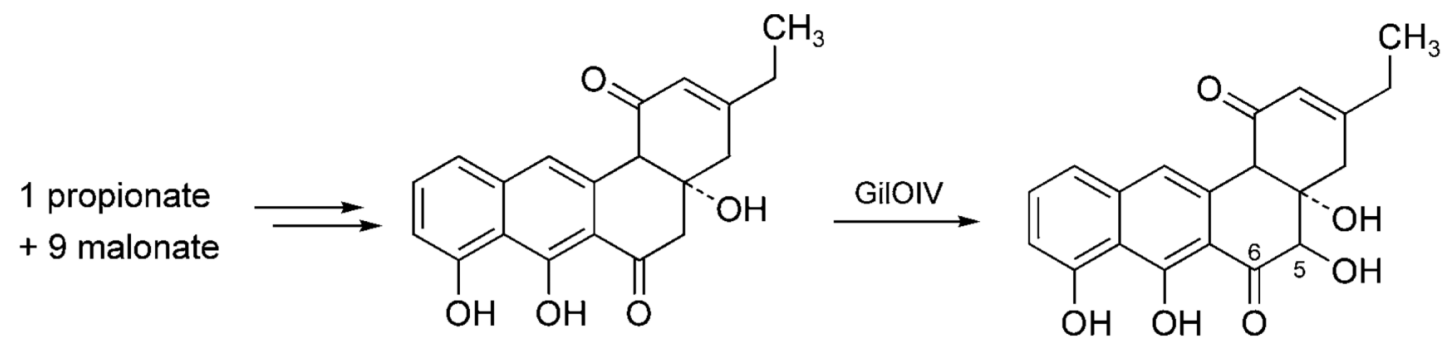

14

15

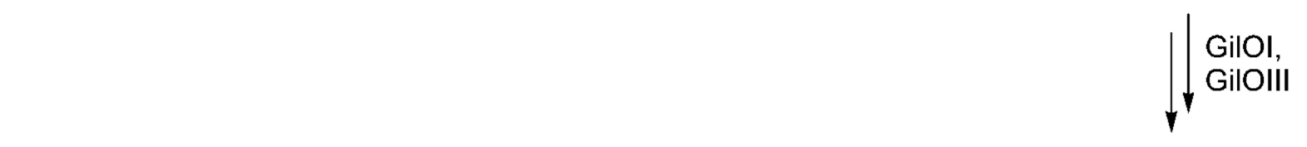<smiles>C=Cc1cc(O)c(C=O)c(C=C(C)c2cc(O)c3c(O)cccc3c2O)c1</smiles>

18

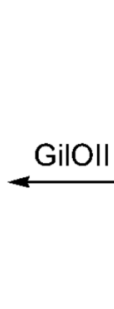<smiles>C=Cc1cc(O)c(-c2cc3cccc(O)c3c(O)c2C(=O)O)c(C(=O)O)c1</smiles>

17<smiles>C=Cc1cc(O)c2c(c1)C(O)OC(=O)c1c-2cc2ccc(C)cc2c1O</smiles>

16<smiles>CCc1cc(O)c(-c2cc3cccc(O)c3c(O)c2C(=O)O)c(C(=O)O)c1</smiles>

19

Scheme 3.

Proposed pathway for the GV biosynthesis. GilR catalyzes the very last step of the pathway. 


\section{Table 1}

Kinetic parameters of GilR.

\begin{tabular}{|c|c|c|c|c|}
\hline Substrate & $\boldsymbol{K}_{\mathrm{m}}[\boldsymbol{\mu \mathrm { M }}]$ & $V_{\max }\left[\mu \mathrm{M} \min ^{-1}\right]$ & $k_{\text {cat }}[a]\left[\min ^{-1}\right]$ & sp. activity $\left[\mathrm{U} \mathrm{mg} \mathbf{~}^{-1} \mathrm{~min}^{-1}\right]$ \\
\hline 11 & $117.0 \pm 24.8$ & $268.31 \pm 40.77$ & $2.29 \pm 0.03$ & $3.62 \pm 0.88$ \\
\hline 12 & $93.4 \pm 12.73$ & $61.24 \pm 6.28$ & $0.65 \pm 0.086$ & $0.84 \pm 0.10$ \\
\hline 13 & n.d. & n.d. & n.d. & $1.4 \times 10^{-3}$ \\
\hline
\end{tabular}

